\title{
Cognitive Styles on C-Test and Cloze-Elide Test: Which Style Acts Better?
}

\author{
KAMAL HEIDARI SOURESHJANI \\ Islamic Azad University, Shahrekord Branch, Shahrekord, Iran
}

\begin{abstract}
Bio Data:
Kamal Heidari Soureshjani holds an M.A. in TEFL from Shiraz University and is a Young Researchers Club Member. He has taught English courses and IELTS at different institutes in Shiraz and is presently the academic member of Islamic Azad University, Shahrekord Branch.
\end{abstract}

\begin{abstract}
The study was, in fact, an attempt to investigate any probable role of the cognitive style of language learners in their performance of two varieties of cloze test; that is, c-test and cloze-elide test. In other words, the study tried to see if being an FD or FI cause any significant difference in their performance on such two tests or not. To achieve such a purpose, 95 language learners were selected on the basis of availability sampling procedure and then their cognitive style was determined by using Group Embedded Figure Test (GEFT). After that, a series of c-test and cloze-elide tests were distributed among the two types of learners. In the end, the study revealed that there is a significant difference between the cognitive style of learners and their performance on the two intended tests. The study also showed that with regard to c-tests, FI learners have a better performance in comparison to FDs. However, regarding the cloze-elide test, FD learners outperform FIs.
\end{abstract}

Keywords: C-test; Cloze-elide test; Cognitive style; GEFT

\section{Introduction}

\section{Cognitive Style}

Among assorted factors which may affect the performance of a person in language use is the individual differences. These differences are said to be of remarkable significance in designing, developing, and implementing of materials and curricula (Skinner 1954). Further, it is axiomatic that each person has his own ways and strategies to approach and process information. Accordingly, one of the most significant aspects of any kind of pedagogy is to take into account the impact of these differences on the learning and teaching processes (Snow, 1997).

However, an example of individual differences is cognitive styles and especially being a field independent (FI) or field dependent (FD). Auburn and 
Ausburn (1978) defined cognitive styles as the psychological dimensions that represent the consistencies in an individual's manner of acquiring and processing information (p. 338). According to Messick (1984), cognitive style deals with the manner in which people prefer to make sense out of their world by collecting, analyzing, evaluating, and interpreting data. These styles are thought to remain consistent preferences throughout life (Jonassen \& Grabowski, 1993). Cognitive style is also considered as a notion referring to the way in which people perceive, conceptualize, organize, and recall information.

There have been mentioned assorted categories for different cognitive styles. Some examples are: leveling and sharpening learners, visualizers and verbalizers, serialists and holists. However, the dichotomy which has received the greatest attention in SLA is field dependence and independence category. Ellis (1986) stated that FDs are personal orientated. That is, they rely on external frame of reference in processing information; they are also holistic and perceive a field as a whole. They are dependent i.e. the self-view is derived from others. They are socially sensitive and have more capable skill in interpersonal and social relationships. FD people are more attentive to social cues. They more readily tell others about themselves, reflecting greater emotional openness, and they prefer to be with people. It seems reasonable to hypothesize that the interpersonal orientation of FD people may increase the development of effectiveness in social behavior. In support of this hypothesis there are some findings of Goodenough and Witkin (1976) which show FD people may get along better with others and are more successful in occupations. FD people are also more likely to outperform in recalling social information like relationships and conversations. They also consider problems in a more global way by considering the whole picture of the identified context. In contrast, based on Goodenough and Witkin (1976), people are called FI if they are able to abstract an element from its context, or background field. Therefore, they are willing to be more analytic and approach problems in a more analytical way.

\section{Cloze Test and its Varieties}

Testing is a prevalent phenomenon in our lives, as well as in the language learning process. McNamara (2000) exemplifies that there are a number of reasons for administering language tests, which play a significant role in an individual's social and working life. Language teachers cooperate with language tests since they need to evaluate their learners; language testing is also carried out for research purposes. Among the existence of scads of tests proposed for assessing the performance of testees on reading side of language, one of the most popular methods which have gained wide popularity because of its reliability, sufficient validity and remarkable practicality is the cloze procedure. Cloze tests may have different formats, but they all consists basically on a reading text in which every nth word (usually the seventh) has been left blank and it is the learner's job to supply either the exact word or any other which is appropriate in order to complete the text. Then, cloze test is often defined as a text or a passage of appropriate length and difficulty with every nth word deleted (Farhady, 1996). The definition seems quite straightforward. However, certain precautions should be taken regarding the concepts of appropriate length, difficulty, and the value and the frequency of $n$. 
As to the varieties of this kind of test, there are two main types of cloze test: C-test and Cloze-Elide test. The former consists of four to six short texts students might have seen before, in which instead of whole words, it is the second half of every second word which is deleted, beginning with the second word of the second sentence; both the first and the last sentences of the text are left intact. This is one of the techniques we have chosen to assess content knowledge and language use. It is claimed that the $\mathrm{C}$-test has some advantages over the cloze test since regarding the variety of passages, a better sampling of content areas, styles, genres and certain and certain vocabulary items can be covered. There is also a more representative sample of all language elements since it is every second word which is removed; scoring is easy and objective because there is usually only one correct response. Unlike cloze tests, learners seem to enjoy doing C-tests -either as a classroom task or as a more formal assessment activity-, which in turn has a beneficial backwash effect on learners.

The latter variety is known as the cloze-elide test. In this type, instead of deleting a set of words from the passage, a certain number of words are added to the text. The testees are required to read the text and identify the extra or redundant words and cross them out. In fact, in the cloze-elide test, the processing of the text is somewhat opposite to that of the standard cloze test. In the cloze test, the testees should read the text and add some words; whereas in the cloze-elide test, the testees should read the text and delete some words. Since the cloze-elide test is different from the varieties of the cloze test mentioned here, certain points should be taken into account in developing and using a cloze-elide test.

Despite the popularity of cloze procedure as a test, many language educators are not well aware of its merits and demerits in a rage of domains. One of the domains in which cloze procedure has been, at least partly, neglected is the impact of the cognitive style (FD/FI) of testees on their performance on cloze tests. Therefore, this paper is an attempt to provide its readers, especially language teachers, with some useful information about the same issue. More specifically, the paper addresses the following research questions:

1) Does the cognitive style of testees bear any influence on their performance on a c-test?

2) Does the cognitive style of testees affect their performance on a cloze-elide test?

\section{Literature Review}

\section{Cognitive Style}

The cognitive style of language learners may affect the language performance of individuals. Cognitive style is a notion referring to the way in which people perceive, conceptualize, organize, and recall information. The dichotomy which has received the greatest attention in SLA is field dependence and independence category. A number of hypotheses about the role of field dependence/ independence in SLA have been made. Herman Witkin conducted much of the original research in this area in the 1950s. A field-dependent person, according to him, has difficulty in finding a geometric shape that is embedded or hidden in a 
background with similar (but not identical) lines and shapes. The conflicting patterns distract the person from identifying the given figure. However, a person who is field-independent can easily identify the geometric shape, regardless of the background in which it is set.

The notions of field dependence and field independence, as one of the cognitive style dimensions, has been investigated by different researchers and is considered as an important factor while contemplating educational issues (Witkin \& Goodenough, 1976). Chinien and Boutin (1983) state that FD and FI seems to hold promising potential for the design and development of telling instructional materials. Messick (1976), highlighting the significance of FD and FI, differentiates FD and FI in this way that "The field independence person tends to articulate figures as discrete from their backgrounds and to easily differentiate objects from embedding contexts, whereas the field dependent person tends to experience events globally in undifferentiated fashion. Field independent individuals have more facility with tasks requiring differentiation and analysis (P. 5)."

Summerville (1999) referred to field independence and field dependence as a global versus an articulated style that represents the extent to which an individual's processing of information is influenced by the contextual field. FI learners have been described as "analytical, competitive, individualistic, task oriented, internally referent, intrinsically motivated, hypothesis testing, self-structuring, linear, detail oriented, and visually perceptive" (Hall, 2000, p. 5) whereas FD learners have been referred to as "group-oriented, global sensitive to social interactions and criticism, extrinsically motivated, externally referential, not visually perceptive, non-verbal, and passive learners who prefer external information structures" (Hall, 2000, p. 6). Governor (1998) added that FD learners are in more need of social input and external help in interpreting clues embedded in a particular learning task. $\mathrm{Hu}$ (1998) observed that FI learners are more analytic and rely less on external clues than their FD counterparts. FI learners, it appears, are more able to generate and structure their own knowledge rather than accepting knowledge reprocessed by others.

A number of studies, however, have also maintained that the distinction between Field-Dependent and Field-Independent individuals is similar to that of differentiating Holists and Serialists (Riding \& Agrell, 1997). Field-Dependent individuals typically see the global picture, ignore the details, and approach a task more holistically. Field-Independent individuals tend to discern figures as being discrete from their background, to focus on details, and to be more serialistic in their approach to learning.

\section{Cloze Test}

Cloze testing was first introduced by Taylor (1953), who developed it as a reading test for native speakers. He defined the term "cloze" from a gestalt concept which teaches that an individual will be able to complete a task only after its pattern has been discerned: A cloze unit may be defined as: any single occurrence of a successful attempt to reproduce accurately a part deleted from a 'message' (any language product), by deciding from the context that remains, what the missing part should be (p. 416).Cloze tests consist of a text (usually two or three paragraphs) which has had words or parts of words deleted from it. Students or test subjects must then 
draw upon their knowledge of the language to write words which appropriately fill in the blanks.

There are, however, at least five main types of cloze tests available to language teachers: The fixed-rate deletion, the selective deletion (also known as the rational cloze), the multiple-choice cloze, the cloze elide and the C-test (Ikeguchi 1995; Weir 1990; Klein-Braley and Raatz 1981). In this paper just the last two varieties are touched upon.

C-Tests were developed for the first time in 1981 by Raatz and Klein-Braley. As an alternative integrated approach the C-Test is acceptable in that it "... is based upon the same theory of closure or reduced redundancy as the cloze test" (Alderson, 2000: 225). Test-takers are asked to restore the second half of every second word deleted beforehand. Alderson (2000) and Cohen (2001) point out that C-tests are more reliable and valid than cloze tests in terms of assessing but are thought to be more irritating than cloze tests. In the marking process, the testers do not face difficulties since they expect to see the restored word (Weir, 1990). Klein-Braley and Ratatz (1981) found that the way classical cloze tests are constructed, i.e., deleting every $n$th word in a reading text, brings about unsatisfactory performance on the part of test takers. Recent research confirms her findings. Khodadady (2007), for example, administered three cloze tests to eight intermediate adult ESL learners to explore the relationship between listening comprehension ability and vocabulary knowledge. The written cloze tests were developed on tape scripts to which learners had listened one week before taking the test.

The cloze-elide (Manning, 1987; Davies, 1975; Bowen, 1978; Elder \& von Randow, 2008) is an objective language test task whereby superfluous, incorrect words are inserted into a text and must be identified by the test taker within a limited time. This technique was introduced as the 'Intrusive Word Technique' and is also called as "...'text retrieval', 'text interruption', 'doctored text', 'mutilated text' and 'negative cloze'..." (Alderson, 2000: 225). The tester inserts words and the testtaker is asked to find the words that do not belong to the text. It is important to be sure that the inserted words do not belong to the text. Otherwise, the test-takers will not be able to identify the inserted words. This task got its name because originally test takers were expected to cross out the superfluous words on paper, which was called "eliding" (Manning, 1987). In the only large scale study focusing on the clozeelide task, Manning (1987) compared scores of more than 1,200 ESL students in U.S. universities and found that the task was useful as a reliable and efficient predictor of other English proficiency measures, such as TOEFL scores, graded essay scores, and teacher judgments of student proficiency.

While now seen as an inauthentic and indirect assessment of language ability, Manning (1987) was at the time considering the cloze-elide task as a way of testing language more directly: He was examining the possibility that this task could address deeper linguistic processing than the ubiquitous multiple-choice questions dominating standardized language testing at that time. Bowen (1978) also presented this task as a more communicative alternative to the standard testing practice of the day.

As to the scoring procedure of cloze tests, there have been traditionally two distinct methods for evaluating cloze tests: Exact Word scoring and the Acceptable 
Word scoring method. For several years there has been some debate about the validity of these scoring systems. For example, Ikeguchi (1995) and Owen et al. (1996), state that when exact word and acceptable scoring systems are compared, there is almost always a very high correlation between the cloze test scores. On the other hand, some researchers (like Alderson 1979; Klein-Braley and Raatz, 1981) claim that neither the exact word nor acceptable method are very reliable, since most cloze test designs themselves are flawed. Klein-Braley and Raatz (1997) assert that:

- Scorers do not agree with individual solutions on SEMAC scoring

- Exact Word scoring is frustrating for learners and scorers alike

-Correlations between two cloze tests often could not be demonstrated in their studies (p. 135).

\section{Method}

\section{Participants}

Altogether 95 students took part in the study as the participants. They were both male and female and ranged from 19 to 25 in age. They, who were selected based on the availability sampling procedure, were B.A students majoring in English Translation in State University of Shahrekord. Besides, in order to determine how many of them were FD and how many FI, Group Embedded Figure Test (GEFT) was used (explained below) and it turned out that of the whole number of participants, 51 learners were FI and 44 FD.

\section{Materials}

The instrument used to gather the intended data was Group Embedded Figure Test (GEFT) which was used to distinguish FI and FD learners. This instrument developed by Witkin, Raskin, and Oltman (1971). They reported a Spearman-Brown reliability coefficient of 0.82 for their instrument. In their study, Witkin, et al. (1971) reported a mean GEFT score of 12.0 for males $(\mathrm{N}=155)$ and a mean of 10.8 for females $(\mathrm{N}=242)$. As to this test, it is a pencil-and-paper test comprising three sections. The first section is for practice and takes two minutes. The second and third consist of 18 items each one having nine items and there are both 5 minutes long (the test totally lasts 12 minutes). In this kind of test, the subjects have to break the pattern to search for features of an embedded target shape. One of the patterns and the shape which students have to find are below as an example:

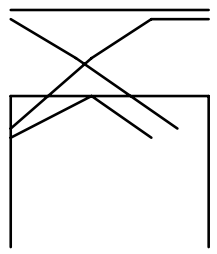

Find the simple picture " $\mathrm{D}$ "

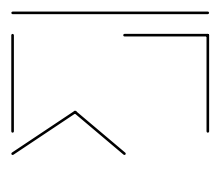

Picture "D"

The scores comprise the number of correct answers, ranging from zero to 18 . A high score indicates FI and a low score indicates FD. Based on the scores on this 
test, the subjects were recognized as FI (a score of 11 and above) or FD (a score of below 11). The cut-off point 11 is usually chosen based on earlier researchers. Based on the obtained scores from GEFT as it was already mentioned, 44 students were judged as FD and 51 students as FI.

The other instruments employed in the study were a c-test and a cloze-elide test exam distributed among the participants. Regarding the c-test, it consisted of two c-tests inserted in the same paper. One of them incorporated 15 blanks and the other consisted of 10 blanks. As to the cloze-elide test, it also included two samples, in the same paper, one involving 14 intrusive words and the second 11 superfluous words.

Finally, the reliability and validity of the tests were also examined. To do so, 30 students were randomly selected and they were given the tests. These students were chosen from Islamic Azad University of Shahrekord and were both male and female and like the main participants, were B.A students in almost the same age range. For the c-test, the reliability turned out to be .84 and for the cloze-elide test .78 (using Cronbach alpha). With regard to their validity, both tests were looked into by some professors of the same university who were expert at testing and they were confirmed to be suitable for the present paper purpose.

\section{Procedure}

In the beginning of the administration session, first the c-test was distributed among the two groups of participants (FDs and FIs). Before that, they were expounded in detail about the purposes of the project and also the importance of their responses. Having finished with the c-tests, they were given the cloze-elide test to answer. Besides, they were given half an hour for each of the test administrations.

After gathering the required data, the statistical package for social sciences (SPSS) version 16 in general and two Independent $t$-tests in particular were run. To be more detailed, to see whether the cognitive style of students bear any influence on their performance on c-tests, one independent t-test was run. Besides, another independent $\mathrm{t}$-test was also run to examine the same point on the cloze-elide tests.

\section{Results}

To present the results of the study, the research questions of the study mentioned in the initial sections of the study are individually brought in and then by considering the related obtained findings of the study are answered. The first research question was:

1) Does the cognitive style of testees bear any influence on their performance on a c-test?

Regarding the first question in this research, it aimed at exploring the fact that if the cognitive style of testees influence significantly their performance on c-test. In fact, it was intended to check whether FD/FI is a significant factor in the learners' performance on such a test. To gain knowledge on this point, independent t-test was run. Table 1 represents the results of the test. 
Table 1

Independent t-test for FD/FI and C-test

\begin{tabular}{|c|c|c|c|c|c|c|c|}
\hline & & T & Df & $\begin{array}{c}\text { Sig. (2- } \\
\text { tailed) }\end{array}$ & $\begin{array}{c}\text { Mean } \\
\text { Difference }\end{array}$ & $\begin{array}{c}\text { Std. Error } \\
\text { Difference }\end{array}$ & \multicolumn{2}{|c|}{$\begin{array}{c}\text { 95\% Confidence } \\
\text { Interval of the } \\
\text { Difference }\end{array}$} \\
\cline { 5 - 8 } & & & Lower & Upper \\
\hline $\begin{array}{c}\text { C-test } \\
\text { performance }\end{array}$ & -.571 & 7 & .01 & -.32 & .56 & -1.46 & .80 \\
\hline
\end{tabular}

As the table shows, a significant difference is observed between the two factors of the study $(\mathrm{t}=-.57, p<0.05)$. To put it another way, the table implies that being an FD or an FI learner do affects their performance on a c-test. Now to see which style outperforms the test, Table 2, which shows the descriptive statistics, is represented.

Table 2

Descriptive Statistics of C-test Performance \& Cognitive Style

\begin{tabular}{|c|c|c|c|c|c|}
\hline & Style & $\mathrm{N}$ & Mean & $\begin{array}{c}\text { Std. } \\
\text { Deviation }\end{array}$ & $\begin{array}{c}\text { Std. Error } \\
\text { Mean }\end{array}$ \\
\hline \multirow{2}{*}{$\begin{array}{c}\text { C-test } \\
\text { performance }\end{array}$} & FI & 51 & 7.6 & 1.32 & .29 \\
\cline { 2 - 6 } & FD & 44 & 4.6 & .95 & .21 \\
\hline
\end{tabular}

As the table reveals, since the mean value of FI learners (Mean $=7.6$ ) is to a large extent higher than that of FD learners (Mean $=4.6$ ), therefore, it can be concluded that FI language learners outperform on c-tests in comparison to FDs.

As with the same issue on cloze-elide test, the research question posed in the study was:

2) Does the cognitive style of testees affect their performance on a cloze-elide test?

The question tries to shed light on any probable effect of the cognitive style of testees and their performance on cloze-elide tests. Like the first research question, Table 3 reveals the main statistics of independent $t$-test for this question.

Table 3

Independent t-test for FD/FI and Cloze-Elide test

\begin{tabular}{|l|l|l|l|l|l|l|}
\hline & T & Df & $\begin{array}{c}\text { Sig. (2- } \\
\text { tailed) }\end{array}$ & $\begin{array}{c}\text { Mean } \\
\text { Difference }\end{array}$ & $\begin{array}{c}\text { Std. Error } \\
\text { Difference }\end{array}$ & $\begin{array}{c}\text { 95\% Confidence } \\
\text { Interval of the } \\
\text { Difference }\end{array}$ \\
\cline { 4 - 6 } & & Lower & Upper \\
\hline
\end{tabular}




\begin{tabular}{|c|c|c|c|c|c|c|c|}
\hline $\begin{array}{c}\text { Cloze-elide } \\
\text { test } \\
\text { performance }\end{array}$ & -.531 & 7 & .00 & -.42 & .66 & -1.44 & .73 \\
\hline
\end{tabular}

The table indicates a significant difference between the two factors of the study $(\mathrm{t}=-.53, p<0.05)$. Therefore, like the first research question, being an FD or an FI learner do bear influence on their performance on a cloze-elide test. Now to see which style outperforms the test, Table 4 is brought.

Table 4

Descriptive Statistics of Cloze-Elide test Performance $\mathcal{E}$ Cognitive Style

\begin{tabular}{|c|c|c|c|c|c|}
\hline & Style & $\mathrm{N}$ & Mean & Std. Deviation & Std. Error Mean \\
\hline \multirow{2}{*}{$\begin{array}{c}\text { Cloze-elide test } \\
\text { performance }\end{array}$} & FI & 51 & 5.5 & 1.29 & .26 \\
\cline { 2 - 6 } & FD & 44 & 6.2 & .89 & .22 \\
\hline
\end{tabular}

As the table reveals, since the mean value of FD learners (Mean $=6.2$ ) is to a large extent higher than that of FI learners (Mean $=5.5$ ), therefore, it can be concluded that FD language learners outperform on cloze-elide tests in comparison to FIs.

\section{Discussion and Conclusions}

The study was, in fact, an attempt to investigate any probable role of the cognitive style of language learners in their performance of two varieties of cloze test; that is, c-test and cloze-elide test. In other words, the study tried to see if being an FD or FI cause any significant difference in their performance on such two tests or not. Distributing a series of c-test and cloze-elide tests among the two types of learners (FDs and FIs), the study revealed that there is a significant difference between the cognitive style of learners and their performance on the c-test. To be more detailed, FI learners have a better performance in comparison to FDs on this variety of cloze test. Despite the lack of any specific previously done study on the same issue, some justifications can be brought up for this conclusion. As an example, it was already mentioned in the early sections of the study that FI learners tend to articulate figures as discrete from their backgrounds and to easily differentiate objects from embedding contexts (Messick, 1976). Or as Goodenough (1976) rightly argue, people are called FI if they are able to abstract an element from its context, or background field. Therefore, they are willing to be more analytic and approach problems in a more analytical way. Therefore, regarding these characteristics of FI learners, it can be illuminated that because in c-tests learners are expected to insert suitable words in their suitable places one by one, FIs can employ their analytic ability and by considering the blanks in the related sentences, identify the missing elements of the sentence.

The study results also showed that the learners' cognitive style also significantly affect their performance on cloze-elide tests. In other words, FD language learners outperform FIs on this kind of test. Like the previous case, it was already exemplified that FD learners rely on external frame of reference in 
processing information and are also holistic and perceive a field as a whole; they are socially sensitive and have more capable skill in interpersonal and social relationships. In other words, FD people are more attentive to social cues. Witkin and Goodenough (1976) also show that FD people consider problems in a more global way by considering the whole picture of the identified context. Considering these features, it can be concluded that since FDs consider the whole picture of clozeelide tests and form a whole picture of the text rather than having separate pictures of different parts of a text, they would be able to identify more easily the intrusive words inserted in cloze-elide tests than FIs.

Furthermore, the reasoning tendencies of FDs and FIS can also be regarded as another justification for the obtained findings of this study. As Nilforooshan and Afghari (2007) argue, the specific type of reasoning, inductive or deductive reasoning, favored by each of FD and FI learners. In deductive reasoning, one considers the individual parts from the whole, that is, he/she reaches a conclusion by having a general principle in mind. Deductive reasoning is inferring specific facts from a general principle. Therefore, FIs use their repertoire of information processing strategies, restructuring ability, analytical way of thinking, and creativity which is derived from the individual development of criteria on a rational basis. They also have the capacity to extract a part from a whole or field and restructure it themselves. Therefore, it is assumed that they have a deductive reasoning and they may use this capacity in performing c-tests. That is, by analyzing the different sentences of c-tests and restructuring them in their minds, they can identify the missing words of each sentence.

On the other hand, in inductive reasoning one makes a generalization based on the individual observations he has made and general principles are derived from particular facts or instances (Brown, 1994). On the other hand, field dependent learners are less able to extract a part from the whole. It is assumed that they think inductively since they seem to be concerned about finding parts by external cues to make a whole. They are not aware that one of the parts they are placing within the other parts is the same they are looking for. As a result, they, by imaging the whole cloze-elide tests in their minds, are more capable to identify irrelevant words included in the tests than FIs.

In the end, a host of topics may be suggested for conducting further studies with regard to cognitive style types. A basic one is to make a relative comparison between the FD and FI learners in terms of some other tests like composition tests, summarization tests, etc. Besides, the investigation of cognitive styles as a significant factor in other skills including reading, speaking, and listening can also be another suggested topic. 


\section{References}

Auburn, L. V., \& Ausburn, F. B. (1978). Cognitive styles: Some information and Implications for instructional design. Educational Communications and Technology Journal, 26, 336-354.

Alderson, J. C. (1979). The cloze procedure and proficiency in English as a second language. TESOL Quarterly, 13, 219-226.

Alderson, J. C. (2000). Assessing reading. Cambridge: Cambridge University Press.

Bowen, J. D. (1978). The identification of irrelevant lexical distraction: An editing task. TESL Reporter, 12(1), 1-3, 14-15.

Bray, E. (1995). Using limericks to help Japanese students improve their pronunciation. Paper presented at the Annual Meeting of the Japanese Association of Language Teachers, Japan.

Brown, H. D. (1994). Principles of Language Learning and Teaching (3 $3^{\text {rd }}$ ed.). Englewood Cliffs, New Jersey: Prentice Hall Regents.

Chinien, C., \& Boutin, F. (1992). Cognitive style FD/I: An important learner characteristic for educational technologists. Journal of educational technology systems, 21, 303-311.

Davies, A. (1975). Two tests of speeded reading. In R. L. Jones, \& J. B. Spolsky (Eds.), Testing language proficiency (pp. 119-130). Washington, DC: Center for Applied Linguistics.

Elder, C., \& Von Randow, J. (2008). Exploring the utility of a web-based English language screening tool. Language Assessment Quarterly, 5(3), 173-194.

Ellis, R. (1986). Understanding second language acquisition. Oxford: Oxford University Press.

Farhady, H. (1996). Varieties of cloze procedure in EFL education. Roshd Foreign Language Teaching Journal, 12, 217-229.

Goodenough, D. R. (1976). The role of individual differences in field dependence as factor in learning and memory. Psychological Bulletin, 83, 675 - 694.

Governor, D. (1998). Cognitive styles and metacognition in web based instruction. Retrieved from http://www.members.cox.net/vogannod/THESIS.html

Hall, J. K. (2000). Field dependence-independence and computer-based instruction in geography [Doctoral Dissertation]. Virginia Polytechnic Institute and State University, the United States.

$\mathrm{Hu}, \mathrm{J}$. (1998). The relationship between hypermedia features and the learning style/cognitive control of hypermedia developers [Unpublished doctoral dissertation]. West Virginia University, the United States.

Ikeguchi, C. (1995). Cloze testing options for the classroom. In J. D. Brown, \& S. Yamashita (Eds.), Language testing in Japan (pp. 166-178). Tokyo: The Japan Association for Language Teaching.

Jonassen, D. H., \& Grabowski, B. L. (1993). Handbook of individual differences, learning, and instruction. Hillsdale, NJ: Lawrence Erlbaum.

Khodadady, E. (2007). C-tests: Method specific measures of language proficiency. IJAL, 10(2), 1-26.

Manning, W. H. (1987). Development of cloze-elide tests of English as a Second Language. (TOEFL Research Report 23). Princeton, NJ: Educational Testing Service. 
Klein-Braley, C. (1997). C-Tests in the context of reduced redundancy testing: An appraisal. Language Testing, 14, 47-84.

Klein-Braley, C., \& Raatz, U. (1984). A survey of research on the C-Test. Language Testing, 1, 134-146.

McNamara, T. (2000). Language testing. Oxford: Oxford University Press.

Messick, S. (1976). Individuality in learning: Implications of cognitive style and creativity for human development. San Francisco, CA: Jossey-Bass.

Messick, S. (1984). The nature of cognitive styles: problems and promise in educational practice. Educational Psychologist, 19(1), 59-74.

Nilforooshan, N., \& Afghari, A. (2007). The effect of field dependence-independence as a source of variation in EFL learners' writing performance. IJLS, 1(2), 103118.

Owen, C., Reeves, J., \& Widener, S. (1996). Testing. Birmingham, UK: University of Birmingham Press.

Riding, R., \& Agrell, T. (1997). The effect of cognitive style and cognitive skills on school subjects performance. Educational Studies, 23, 311-323.

Skinner, B. F. (1954). The science of learning and the art of teaching. Harvard Educational Review, 24, 86-97.

Snow, R. E. (1997). Individual differences. In R. D. Tennyson, F. Schott, N. M. Seel, \& S. Dijkstra (Eds.), Instructional design: International perspectives (pp. 215-241). Mahwah, NJ: LEA.

Summerville, J. (1999). Role of awareness of cognitive style in hypermedia. International Journal of Educational Technology. Retrieved from http:/ / www.outreach.uiuc.edu/ijet/v1n1/summerville

Taylor, W. L. (1953). Cloze procedure: A new tool for measuring readability. Journalism Quarterly, 30, 415-433.

Weir, C. (1990). Communicative language testing. Hemel Hempstead: Prentice Hall International Ltd.

Witkin, H. A., \& Goodenough, D. R. (1976). Field dependence and interpersonal behavior. (RB 76 - 12). Princeton, NJ: Educational Testing Service.

Witkin, H. A., Oltman, P. k., Rastkin, E., \& Karp, S. A. (1971). Group embedded figures test manual. Palo Alto, CA: Consulting Psychologist Press. 